
\title{
R Reserach S Suare \\ Reflection on the Reform of China's Emergency Medical Insurance System based on the Prevention and Control of COVID-19
}

Luo Meng (D1206109643@qq.com )

Anhui medical univercity https://orcid.org/0000-0001-7215-3936

Hui Cheng

Wenzhou Medical University

Shaohua Li

Anhui medical university

Research article

Keywords: COVID-19, Medical insurance, Reform, China

Posted Date: August 25th, 2020

DOI: https://doi.org/10.21203/rs.3.rs-60012/v1

License: (c) (i) This work is licensed under a Creative Commons Attribution 4.0 International License.

Read Full License 


\section{Abstract}

Objective: Based on the Prevention and Control of COVID-19, this paper points out the shortcomings of China's current medical insurance system, and puts forward the concept of establishing emergency medical insurance system.

Methods: This paper analyzes the characteristics of the modern epidemic and its special requirements for medical insurance. Putting forward the idea of mechanism construction.

Results:The operation of China's national medical insurance system is mainly operated by the insured, the government, medical institutions and medical institutions. However, the rapid spread of the epidemic has caused great disasters to the society. In the face of major public health events, medical insurance should have four characteristics: the "normalization" of the emergency medical insurance system, the fairness of guarantees, the public quality of treatment and positive externalities. China should establish an emergency system in line with these four characteristics from the four parties. Therefore, this paper analyzes the characteristics of modern epidemic risk, its development process and the requirements for the insurance industry in combination with the situation of China's response to dealing with COVID-19, and puts forward that China should further improve the universal medical insurance system and establish an emergency medical security system to better deal with all kinds of sudden public health events, which will still happen in the future.

Conclusions:China's national medical insurance system should not be limited to meet people's conventional medical needs. When public health emergencies occur, it is also necessary to establish a sound medical insurance system to operate.The establishment of emergency medical security system is one of the important development directions of our country in the future.

\section{Background}

Achieving universal health coverage is one of the targets of the World Health Organization.[1]Since 1998, China has formally established the basic medical insurance system for urban employees.[2] In 2003, it began to promote the new rural cooperative medical insurance system (hereinafter referred to as the "NCMS") nationwide.[3] In 2007, it started to pilot the basic medical insurance system for urban residents. The system constitutes the main body of China's public medical security, and China's universal medical security system has initially taken shape.[4] With the reform and development, China put forward its opinions on the integration of the basic medical insurance system for urban and rural residents in 2016 and will continue to in-depth reforms until the three types of insurance are combined into one insurance to better meet the people's growing needs for a better life and provide comprehensive protection people are healthy.[5-6]

In order to achieve the goal of "everyone has access to medical services and the poor bear medical expenses",[7] the Chinese government has established a multi-level medical security system, including a universal medical system, commercial medical insurance, and medical insurance.[8] Charity assistance. 
Urban workers and residents, rural people, poor groups, and patients with serious diseases can all use this universal healthcare system. As of the end of 2019, the number of people in China using this form of basic medical insurance has exceeded 1.35 billion, which accounts for more than $97 \%$ of the total population.[9]

However, the outbreak of COVID-19 infectious diseases in 2019 has caused huge losses to China and the world. China's basic medical insurance system can not longer only cover the people's basic health needs, but also play an insurance role in the face of major public health events to avoid risks and better protect the people.[10]

\section{Methods}

This article mainly analyzed the characteristics of modern epidemic risk and its requirements for the development of the insurance system from the operation of China's medical insurance system during the current COVID-19 epidemic, combined with the operation mechanism of China's basic medical insurance, and proposed suggestions and countermeasures.

\section{Results}

\section{Operation mechanism of basic medical insurance for urban employees}

During the operation of the basic medical insurance system for urban employees in China, [11]the main body of the local government is responsible for organizing, managing, and notifying the fund's overall level, overall planning standards, service scope, payment requirements, fund financing and investment, and performing fee control. The social insurance agency is responsible for the fundraising and operating, and the social security agencies in each region will perform the cost payment and fee control functions. Employers and employees pay insurance premiums to various regional government agencies, and the medical service rights they enjoy are provided by designated medical institutions designated by the government to provide reimbursable medical services, which are supervised and reviewed by the audit department. At the same time, medical institutions, enterprise representatives and employee representatives perform their duties of supervising the use of funds.[12]Operation mechanism of basic medical insurance for urban employees is shown in Fig. 1.

\section{Operation mechanism of NCMS}

China's 2003 document stipulated that the provincial people's government shall formulate management measures for the operation of the new rural cooperative medical system,[13]and establish local rural cooperative medical management committees, which performs organization, coordination, management and guidance, and the local government implemented the establishment of payment standards, payment scopes, and payment standards. Compared with quotas and responsibilities of basic medical insurance for urban employees, NCMS had an additional obligation for financial departments to allocate funds. Each rural family pays insurance premiums in accordance with the rules and regulations and submitted them to the Rural Cooperative Medical Management Committee together with financial allocations. The 
operation of the fund is reported to the Management Committee by the Rural Cooperative Medical Management Committee in a timely manner, and further reports to the People's Congress.[14-15]As is displayed in Fig. 2.

\section{Operation mechanism of basic medical insurance for urban and rural residents}

In 2016, China proposed to merge the basic medical insurance for urban residents with NCMS to basic medical insurance for urban and rural residents, and the merged insurance have unified financing policies, unified protection benefits, unified medical insurance catalog, and unified management (see Fig. 3). [16-17]Moreover, in 2018, various provinces and cities in China integrated the establishment of medical security bureaus, which unified management for the future medical security reform and development, laying the foundation for the merger of the three types of insurance.

From the operation mechanism of China's basic medical insurance, we can see that China's universal medical insurance system focuses on meeting the people's medical security needs in the regular period, and lacks a conventional emergency medical insurance system during major public health periods. If a temporary emergency medical system is adopted, There are two main problems. One is that the temporary emergency system has a certain lag. After the national policy is promulgated, it takes a process to formulate specific policies in various provinces and cities across the country according to their own actual conditions, and some patients will not be able to enjoy full medical protection in time; Second, the temporary emergency system is prone to operational risks. During the epidemic, the rescue mission is urgent, and the medical insurance work is highly professional, which requires high emergency response capabilities of government departments, and swimsuits pose risks and affect the full use of policies. The lack of a normalized emergency medical security system has increased the intensity and difficulty of the work of the medical insurance department, and affected the effectiveness of epidemic prevention and control to a certain extent.[18]

\section{Discussion}

\section{Characteristics of Modern epidemic risk}

Since the birth of mankind, the danger of epidemics has existed objectively, and it has continued to harm human society along with mankind. The globalization of the new crown pneumonia epidemic crisis shows that there are risks in any link in the logical chain of biological virus $\rightarrow$ human disease $\rightarrow$ regional disease transmission $\rightarrow$ global disease transmission.[19]

The occurrence of the risk of the epidemic includes both natural ecological environmental factors and socio-economic factors. Due to the development of social and economic modernization, the risk of the epidemic has also shown new characteristics. One is the global spread. With economic development and social progress, human interactions have become more frequent and the space for activities has expanded. This has created favorable conditions for the spread of infectious diseases in a wide range; the second is rapid spread. Due to the development of land, sea and air transportation technology in modern society, the time for the spread of the epidemic has been shortened, leading to increased pressure 
on epidemic prevention and control; third, the risk impact is comprehensive. Risks begin with infectious diseases that directly endanger human life and health, but they also affect many areas of social life; fourth, huge losses.The epidemic spreads widely, spreads quickly and is susceptible. It affects all aspects of social life and economic operation, and its losses far exceed the risks of general risks and natural disasters.[20-21]

\section{The special requirements of the modern epidemic risk on the medical insurance system}

In modern society, the risk of sudden major epidemics has clear new characteristics, and has special requirements for emergency medical insurance. One is the "normalization" of the emergency medical insurance system. The occurrence of the epidemic cannot be predicted in advance, so emergency medical insurance presents a strong uncertainty.[22-23]But as a kind of risk, the risk of an epidemic exists objectively at all times. This requires the normalization of emergency medical protection to ensure a calm response to the outbreak. The second is the fairness of guarantees. Emergency medical security should be a system that is coordinated at the national level to ensure that all citizens can enjoy fair and reasonable emergency medical security services. The third is the public quality of treatment. During a major epidemic, the emergency medical insurance treatment is a pure public good, and it is non-exclusive in benefit and non-competitive in consumption. Therefore, the government needs to use fiscal funds to provide it. The fourth is positive externalities. Under the risk of the epidemic, ensure the safety of all citizens, ensure that the people do not delay treatment due to cost concerns, and avoid the problem of "poverty due to disasters and diseases" that may be caused by low- and middle-income people, so as to achieve the best society as a whole utility. The fifth is unconventional. Emergency medical insurance allows medical institutions to appropriately break daily rules. During the emergency period of epidemic prevention and control, emergency medical insurance needs to proactively open a "green channel" for medical institutions to avoid being overly controlled by daily rules and affecting the rapid play of the role of the main body of treatment.[24]

It is precisely because of the various special requirements of emergency medical security that the modern risk of epidemics has caused emergency medical security in many aspects, China urgently needs to strengthen the construction of the emergency medical security system!

\section{The future operation mechanism of the universal medical security system}

While guaranteeing basic medical needs, China's universal medical security system needs a stronger operating mechanism to deal with major public health incidents, as shown in Fig. 4. When a major public health incident occurs, the government and medical insurance institutions provide medical service providers as the core target of concern, and at the same time carry out epidemic prevention and control. Medical service providers report the progress of the epidemic to the government in a timely manner for public prevention and control. The government and medical insurance institutions increase the protection of the insured to prevent the return of poverty due to illness or poverty due to illness.

\section{Conclusion}

Medical insurance is a basic institutional arrangement to resolve disease risks and promote people's health. COVID-19 has caused huge losses all over the world. In the face of major public health incidents, 
China should further improve the universal medical security system to meet the emergency medical needs arising from the outbreak of the epidemic. The government, medical insurance institutions, medical institutions, and insureds all need to strengthen their risk awareness. While obtaining basic national security, they also need other supplementary medical security to reduce the losses caused by major public health incidents.

\section{Declarations}

\section{Ethics approval and consent to participate}

Not applicable.

\section{Consent for publication}

All authors have approved the final manuscript and consented for the publication.

\section{Competing interests}

The authors declare that they have no competing interests.

\section{Funding}

No funding

\section{Authors' contributions}

All authors participated in the study conception and design. ML and $\mathrm{HC}$ are co-first authors of the article. $\mathrm{ML}$ and $\mathrm{HC}$ drafted and revised the paper. Professor SL proposed constructive amendments to the draft. All authors read and approved the final manuscript.

\section{Acknowledgements}

We acknowledge the outstanding contributions from experts' proposals.

\section{References}

1.Ten Threats to Global Health in 2019. [(accessed on 1 May 2019)]; Available online: https://www.who.int/news-room/feature-stories/ten-threats-to-global-health-in-2019.

2.Barber SL, Yao L. Health insurance systems in China - A briefing note. Geneva: World Health Organization; 2010. http://www.who.int/healthsystems/topics/financing/healthreport/37ChinaB_YFINAL.pdf (accessed February 2, 2018).

3.Liu Y. Development of the rural health insurance system in China. Health Policy Plan. 2004; 19:159-165. 
4.Yu H. Universal health insurance coverage for 1.3 billion people: What accounts for China's success? Health Policy. 2015; 119:1145-1152.

5.Pan XF, Xu J, Meng Q. Integrating social health insurance systems in China. Lancet. 2016; 387:12741275 .

6.Wang T. China takes a stab at universal healthcare. www.forbes.com Available at http://www.forbes.com/2009/01/22/china-health-care-marketsecon-cx_twdd_0122markets04.html (accessed July 14, 2016).

7.Dong K. (2009). Medical insurance system evolution in China. China Econ Rev, 20(4): 591-97.

8.Jian J, Jianxiang W, Xiaoyi M, Yuding W, Renyong L. (2015). Equality of medical health resource allocation in China based on the Gini coefficient method. Iran J Public Health, 44(4): 445-57.

9.Chen Y, Jin GZ. (2012). Does health insurance coverage lead to better health and educational outcomes? Evidence from rural China. J Health Econ, 31(1): 1-14.

10.Shaw K. The 2003 SARS outbreak and its impact on infection control practices. Public Health. 2006; 120:8-14.

11.Hsiao WCL. The Chinese health care system: Lessons for other nations. Soc Sci Med. 1995; 41:10471055.

12.Ma J, Lu M, Quan H. From a national, centrally planned health system to a system based on the market: Lessons from China. Health Aff. 2008; 27:937-948.

13.Liu Y. Development of the rural health insurance system in China. Health Policy Plan. 2004; 19:159165.

14.Meng Q, Xu K. Progress and challenges of the rural cooperative medical scheme in China. Bull World Health Organ. 2014; 92:447-451.

15.Zhang D, Shi L, Tian F, Zhang L. Care utilization with China's new Rural Cooperative Medical Scheme: Updated evidence from the China Health and Retirement Longitudinal Study 2011-2012. Int J Behav Med. 2016; 23:655-663.

16.Wang $X$, Zheng A, He X, Jiang H. Integration of rural and urban healthcare insurance schemes in China: An empirical research. BMC Health Serv Res. 2014; 14:142.

17.Yang LP, Chen F. Discussion on integration of medical insurance system for urban and rural residents in China. Yi Xue Yu She Hui. 2017; 30:18-21. (in Chinese)

18.Ding Lei, Cai Wei, Jiang Fan. "Thinking about the Novel Coronavirus Infection Epidemic" [J]. "Science in China" 2020 (03).(in Chinese) 
19.Fan VY, Jamison DT, Summers LH. Pandemic risk: how large are the expected losses? Bull World Health Organ. (2018) 96:129-34. 10.2471/BLT.17.199588

20.Burns A, van der Mensbrugghe D, Timmer H. Evaluating the Economic Consequences of Avian Influenza. (Report No. 47417). Washington, DC: The World Bank; (2008).

21.Jonas OB. Pandemic Risk. The World Bank; (2013). Available online at:

http://siteresources.worldbank.org/EXTNWDR2013/Resources/8258024-1352909193861/89369351356011448215/8986901-1380568255405/WDR14_bp_Pandemic_Risk_Jonas.

22. United Nations General Assembly Protecting Humanity From Future Health Crises: Report of the HighLevel Panel on the Global Response to Health Crises. United Nations General Assembly; (2016).

23.World Health Organization Report of the Ebola Interim Assessment Panel. World Health Organization; (2015). [Google Scholar]

24.National Academy of Medicine The Neglected Dimension of Global Security: A Framework to Counter Infectious Disease Crises. Washington, DC: The National Academies Press; (2016).

\section{Figures}

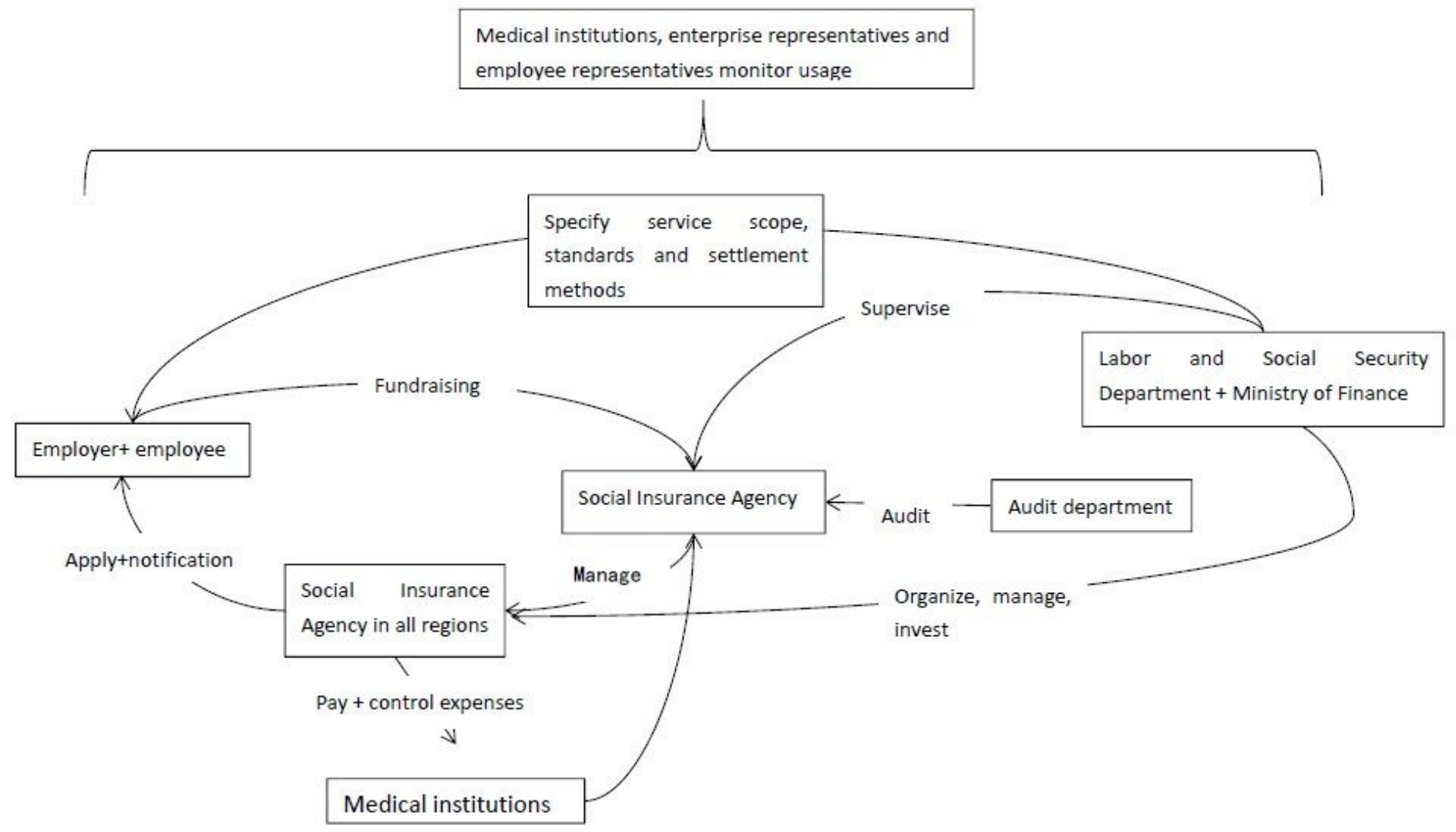

Figure 1 
Operation mechanism of basic medical insurance for urban employees

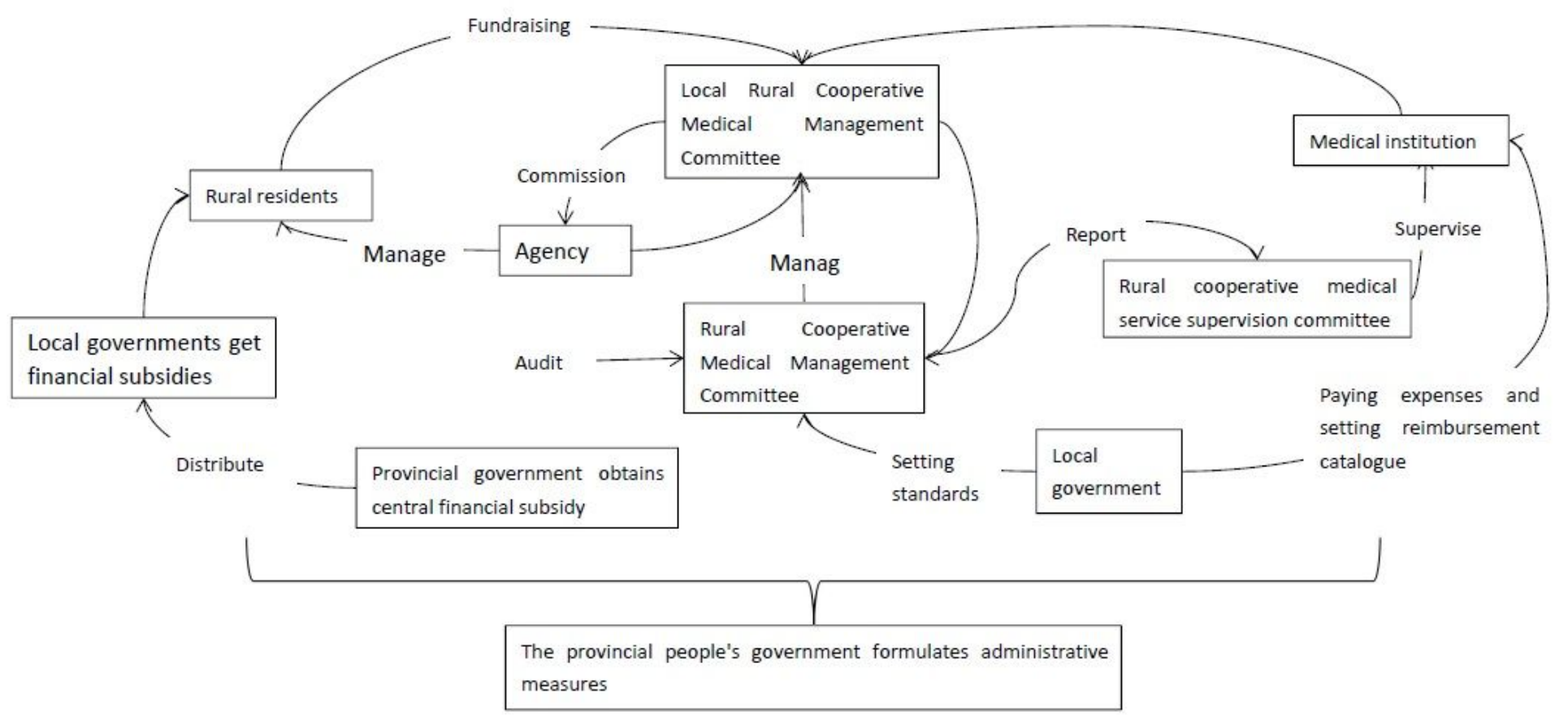

Figure 2

Operation mechanism of NCMS 


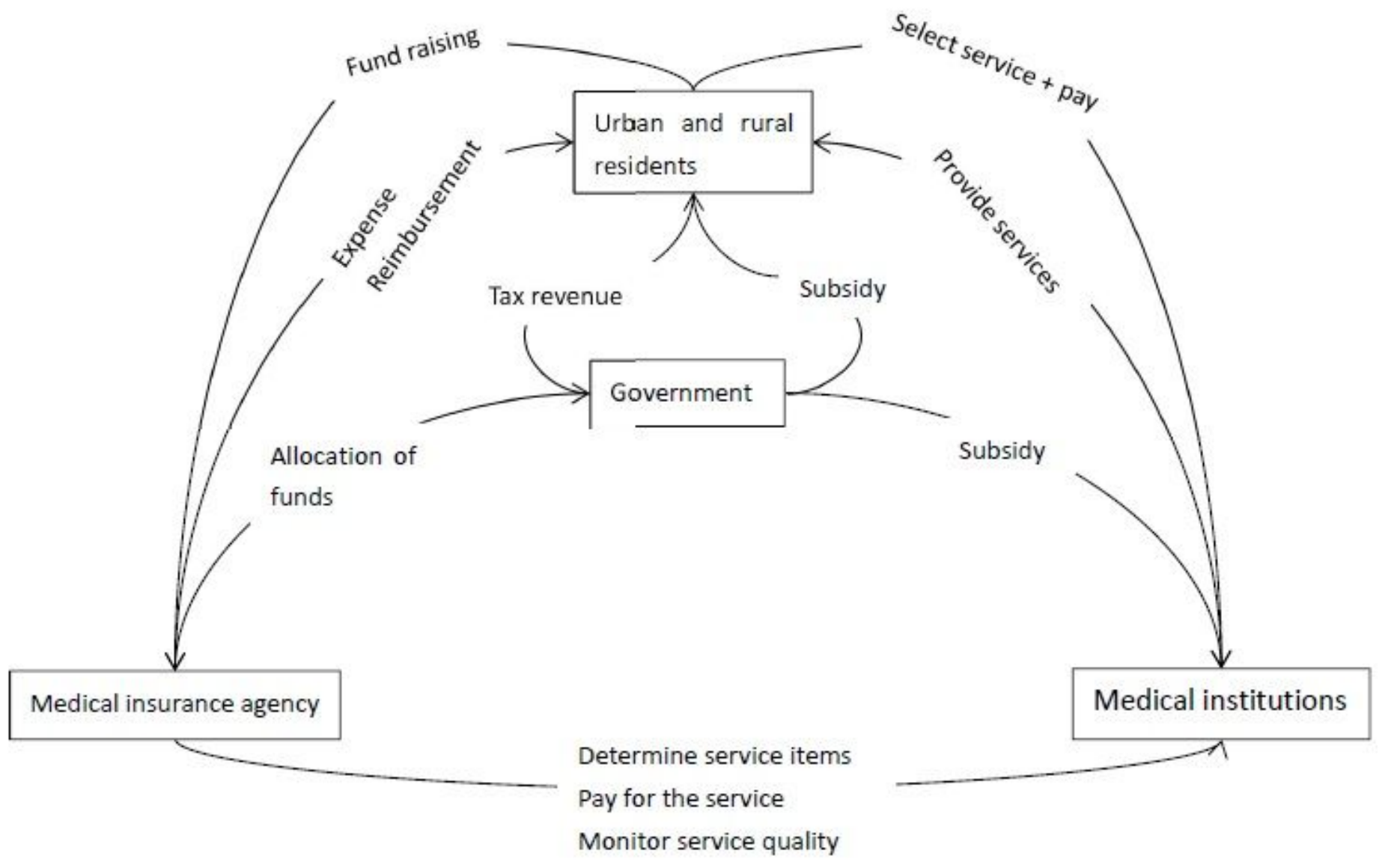

Figure 3

Operation mechanism of basic medical insurance for urban and rural residents

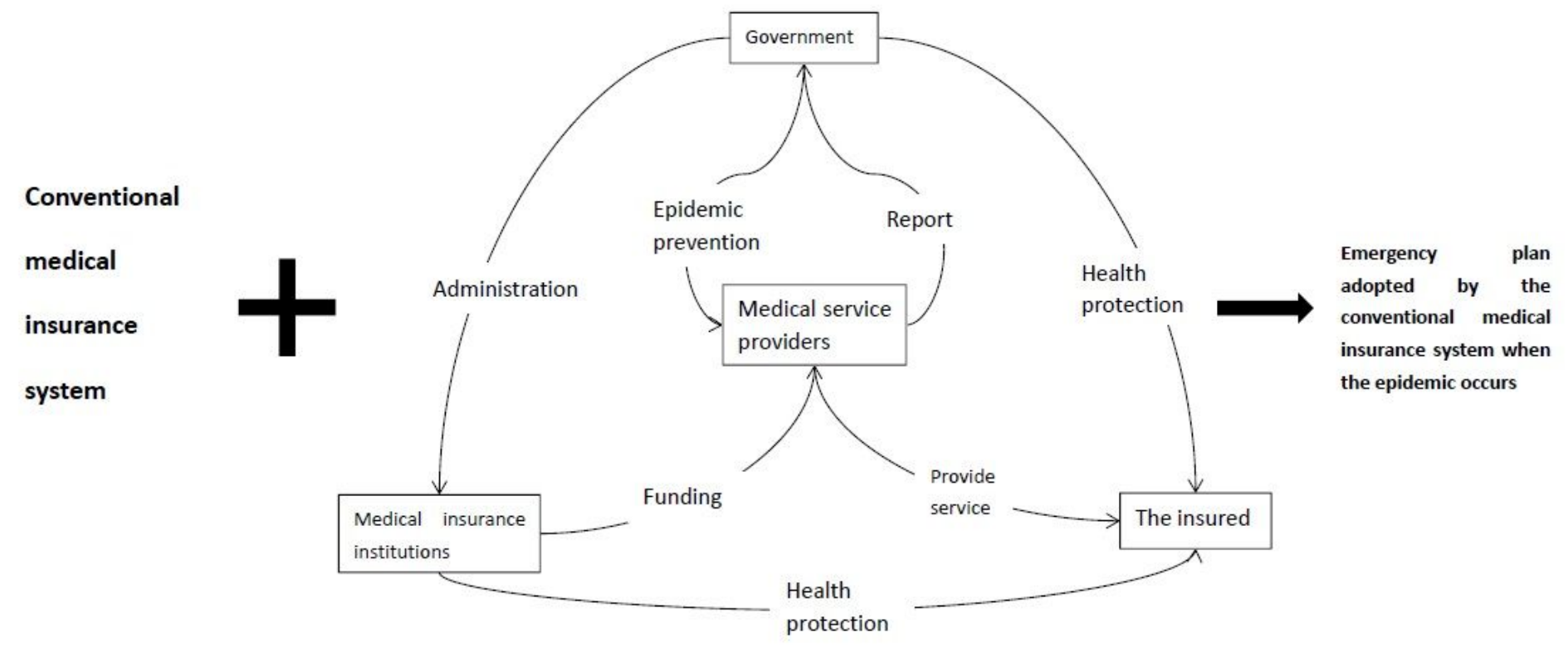

Figure 4 
The future operation mechanism of the universal medical security system 